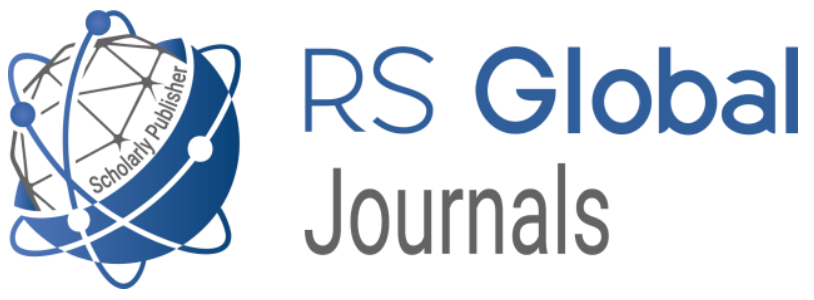

Scholarly Publisher

RS Global Sp. z O.O.

ISNI: 0000000484952390

Dolna 17, Warsaw, Poland 00-773

Tel: +48226022703

Email: editorial_office@rsglobal.pl

JOURNAL International Journal of Innovative Technologies in Social Science

p-ISSN 2544-9338

e-ISSN 2544-9435

PUBLISHER RS Global Sp. z O.O., Poland

$\begin{array}{ll}\text { ARTICLE TITLE } & \text { КРАТКОГО КУРСА АЗЕРБАЙДЖАНСКОГО ЯЗЫКА ДЛЯ } \\ & \text { СТУДЕНТОВ - ИНОСТРАНЦЕВ, ОБУЧАЮЩИХЯ В } \\ & \text { АЗЕРБАЙДЖАНЕ НА НЕГОСУДАРСТВЕННЫХ ЯЗЫКАХ } \\ \text { AUTHOR(S) } & \text { Мусабекова Нармин Чингиз } \\ & \text { Musabayova N. Ch. (2021) At the Crossroads of Linguistic } \\ & \text { Cultures: The Problem of Creation of the Azerbaijani Language } \\ & \text { Brief Course for the Foreign Students Studying in the Non-State } \\ \text { ARTICLE INFO } & \text { Languages in Azerbaijan. International Journal of Innovative } \\ & \text { Technologies in Social Science. 1(29). } \\ & \text { doi: } 10.31435 / \text { rsglobal_ijitss/30032021/7411 } \\ & \text { https://doi.org/10.31435/rsglobal_ijitss/30032021/7411 }\end{array}$

RECEIVED 18 December 2020

ACCEPTED 30 January 2021

PUBLISHED $\quad 05$ February 2021

LICENSE This work is licensed under a Creative Commons Attribution

4.0 International License.

(C) The author(s) 2021. This publication is an open access article. 


\title{
НА СТЫКЕ ЛИНГВОКУЛЬТУР: К ПРОБЛЕМЕ СОЗДАНИЯ КРАТКОГО КУРСА АЗЕРБАЙДЖАНСКОГО ЯЗЫКА ДЛЯ СТУДЕНТОВ - ИНОСТРАНЦЕВ, ОБУЧАЮЩИХСЯ В АЗЕРБАЙДЖАНЕ НА НЕГОСУДАРСТВЕННЫХ ЯЗЫКАХ
}

\begin{abstract}
Мусабекова Нармин Чингиз, дочент кафедры "Иностранные языки-2", канд. филол. наук, Азербайджанский Государственный университет нефти и промышиленности, Баку, Азербайджан, ORCID ID: https://orcid.org/0000-0003-1744-6175
\end{abstract}

DOI: https://doi.org/10.31435/rsglobal_ijitss/30032021/7411

\section{ARTICLE INFO}

Received 18 December 2020

Accepted 30 January 2021

Published 05 February 2021

\section{KEYWORDS}

the Azerbaijani language as foreign, education of foreigners in Azerbaijan.

\begin{abstract}
The article raises the question of the need of the Azerbaijani language for the foreign students studying in Azerbaijan in the non-state languages. The author connects the efficiency of the educational process with confronting the challenges of socio-cultural, learning and psychosocial adaptation of foreigners to the current realities. The author stresses the importance of a nationallyowned Brief Course of the Azerbaijani language for foreign students studying in the non-state languages in the Preparatory Departments of the Azerbaijani universities. As an example, the author refers to her own Program of the Brief Course of the Azerbaijani language for the Chinese students studying in Russian. In the proposed Program, the author indicates a specific lexical and grammatical material, examples of dialogues for conversations that should be assimilated by students. In the last part of the study, educational recommendations to the teachers are suggested and it is also noted the contribution of the ASUOI's teachers of the Russian language as a foreign language in the drawing up the first Program and textbooks on teaching the Azerbaijani language as a foreign language.
\end{abstract}

Citation: Musabayova N. Ch. (2021) At the Crossroads of Linguistic Cultures: The Problem of Creation of the Azerbaijani Language Brief Course for the Foreign Students Studying in the Non-State Languages in Azerbaijan. International Journal of Innovative Technologies in Social Science. 1(29). doi: 10.31435/rsglobal_ijitss/30032021/7411

Copyright: (C) 2021 Musabayova N. Ch. This is an open-access article distributed under the terms of the Creative Commons Attribution License (CC BY). The use, distribution or reproduction in other forums is permitted, provided the original author(s) or licensor are credited and that the original publication in this journal is cited, in accordance with accepted academic practice. No use, distribution or reproduction is permitted which does not comply with these terms.

Введение. С каждым годом все большее количество иностранных учащихся приезжает в Азербайджанскую Республику с целью получения образования на уровне бакалавриата и магистратуры. Некоторая часть студентов избирает в качестве языка обучения азербайджанский, другие же предпочитают учиться на английском или русском языках. Студенты, обучающиеся на негосударственном языке, в процессе обучения испытывают определенные трудности, связанные с попаданием в иную социокультурную и языковую среду. Причиной возникающих проблем зачастую становятся низкий уровень знаний о стране, куда учащиеся приезжают на учебу, разница в менталитете, культурных традициях, правилах поведения. Обучающиеся на неазербайджанском языке не всегда в полной мере могут реализовать в повседневной жизни свои языковые знания, умения и навыки, полученные на уроке, т.к. пребывают в условиях ограниченной языковой среды. Тем важнее становится разработка национально ориентированных учебников и методик преподавания русского и английского языков как иностранных в рамках страны, где эти языки являются иностранными, а также составление 
программы, учебных планов и пособий по краткому курсу изучения языка страны обучения для указанных выше категорий студентов на уровне подготовительного отделения.

Материалы исследований и полученные результаты. Исходя из многолетнего опыта преподавания РКИ студентам из Китая, автор пришел к заключению о необходимости составления программы и учебных материалов по Краткому курсу азербайджанского языка (начальный этап) для китайских студентов, обучающихся в Азербайджане на русском языке. Подобной практики занятий в Азербайджане еще не было. Сегодня иностранцам предлагаются многочисленные курсы изучения азербайджанского языка, ориентирующиеся в своей методике на русскоязычный и англоязычный контингент, причем знания, полученные на этих курсах, предполагают использование азербайджанского языка исключительно в бытовых целях, а не в целях получения образования. Конечно же, подобного рода занятия не могут удовлетворить запросы китайских студентов, слабо владеющих иностранными языками и плохо ориентирующихся в незнакомой стране. Процесс адаптации китайских студентов проходит очень сложно. Можно предположить, что многие адаптационные проблемы связаны с ощущением потерянности в новом культурном пространстве, с непониманием особенностей азербайджанской культуры, традиций, модели поведения в обществе. Мы согласны с преподавателем Чан Динь Ламом [3,170] различающим 5 видов социальной адаптации, через которые необходимо пройти китайским студентам для успешной учебы и адаптации в новом сообществе: 1) учебную (приспособление иностранных студентов к особенностям организации учебного процесса, к формам и методам обучения); 2) ролевую (овладение иностранными студентами социальными требованиями, предъявляемыми к ним); 3) сочиокультурную (включение иностранных студентов в культурную среду общества); 4) социально-психологическую (включение иностранных студентов в среду межличностного общения); 5) социально-бытовую (деятельность в быту, сфере досуга).

Учась на русском языке на подготовительном отделении, китайские студенты в рамках таких предметов, как: "Русский язык", "Научный стиль речи", "Развитие речи" - не только постигают азы и тонкости русского литературного языка, знакомятся с культурой и традициями русского народа, изучают русский язык своей будущей специальности, но и знакомятся с культурой и традициями азербайджанского народа (студенты также посещают уроки по дисциплине "История Азербайджана"). Лингвострановедческая, культурологическая работа проводится не только в рамках аудиторных занятий, но и во внеурочное время (обзорные и специализированные экскурсии, конференции, вечера и т.д.). Тем более необходимым для адаптации студентов-иностранцев становится изучение и использование азербайджанского языка в целях общения.

Автор уже имеет некоторый успешный опыт проведения подобных занятий. Ниже мы предлагаем вариант программы Краткого курса азербайджанского языка для китайских студентов, получающих образование на русском языке на подготовительном отделении. Данная программа и курс построены на основе следующих базовых требований:

1) языковой курс должен носить краткий характер и охватывать основные, наиболее востребованные в речи лексико-грамматические конструкции азербайджанского языка (начальный этап);

2) программа и курс направлены в большей степени на развитие навыков устной речи (чтение, аудирование и говорение), в меньшей степени - письменной речи;

3) все грамматические темы презентуются с помощью соответствующих примеров, моделей на уровне слова, словосочетания, предложения;

4) характер подачи всего языкового материала проводится с учетом особенностей азербайджанского и китайского языков (указываются общие и различные черты);

5) содержание и объём лексических единиц соответствуют реальным потребностям студентов на уровне соответствующей ступени обучения;

6) во время занятий необходимо привлечение большого и разнообразного иллюстративного материала (картинки, таблицы, схемы) и использование аудиовизуальных средств;

7) в рамках урока все новые языковые модели должны "проигрываться" с привлечением уже изученных конструкций в форме диалогов, ролевых игр и т.п. (при необходимости индивидуальных монологов);

8) все виды занятий должны отражать национальную тематику, знакомить студентов с культурой и традициями, особенностями поведения азербайджанцев в тех или иных условиях и ситуациях;

9) по окончание занятия студенты должны получить аудиозапись, содержащую аудиоматериал по пройденным на уроке темам (конструкциям), который должен помочь в закреплении изученного материала в домашних условиях. 
Учитывая большую загруженность студентов в рамках плановых учебных занятий уроки азербайджанского языка можно проводить факультативно раз в неделю в объёме 2 академических часов (45+ 45 мин) или 2 раза по 45 мин. Занятия по азербайджанскому языку можно начинать с третьей недели с начала плановых учебных занятий студентов-иностранцев. Предлагаемый вниманию начальный Курс азербайджанского языка состоит из 23 уроков и рассчитан на 35 часов занятий. Предполагается, что $1 / 3$ урока будет посвящаться презентации нового лексикограмматического материала, а 2/3 времени отводится на закрепление новых и повторение уже пройденных конструкций и моделей (Такое распределение учебного времени не относится к Повторительным урокам.) Повторение пройденного материала может проходить в форме устного выполнения лексико-грамматических тестов, работы с аудиоматериалами (например, аудио-текст с заданиями), в форме проигрывания сводных диалогов, ролевых игр и т.д.

Примерная программа краткого курса азербайджанского языка (для китайских студентов, обучающихся в Азербайджане на русском языке).

1. Азербайджанский алфавит и правила произношения азербайджанских букв/звуков (на примере отдельных букв, слогов, слов). Классификация гласных и согласных (примеры). Введение новой лексики.

2. Личные и притяжательные местоимения (mon $\rightarrow$ monim; son $\rightarrow$ sonin; $\boldsymbol{o} \rightarrow \boldsymbol{o n u n . . .})$.

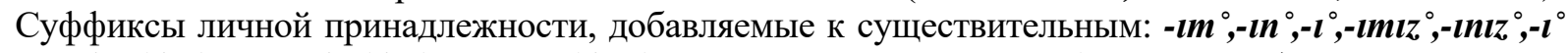
(mənim kitabım, sənin kitabın, onun kita-bı...). "Закон гармонии" ("Ahəng qanunu") и вариативность аффиксов (-lar/-lor; -dvr/-dir/-dur/-dür). Работа над новой лексикой и конструкциями.

3. Имя существительное (Adlıq hal: Kim? Nə? Hara?) (примеры). Образование форм множественного числа (афф.-lar/-lər) (kitab-kitablar; dəftər-dəftərlər) Указательные местоимения

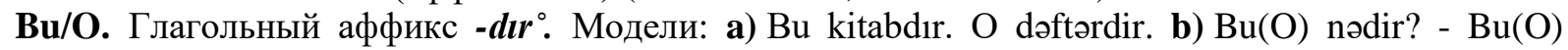
kitabdır. $/ \mathrm{Bu}(\mathrm{O})$ dəftərdir? -Bəli, bu(o) dəftərdir./ $\mathrm{Bu}(\mathrm{O})$ karandaşdır? - Xeyr, bu(o) karandaş deyil, bu(o) gələmdir. (по аналогии можно задать серию вопросов: $\mathrm{Bu}(\mathrm{O})$ kimdir? -.... Bura (Ora) haradır? -...) c) Bu nədir?- Bu çantadır. Bu mənim çantamdır./Bu nədir? - Bu çantalardır. Bu mənim çantalarımdır. Диалоги:" Что это?", "Кто это?" Работа над новой лексикой и конструкциями.

4. Формы приветствия и знакомства (Gəlin tanış olaq./ Tanış olun ../. Sizinlə tanış olmağa şadam./ Sabahın(iz) xeyir./ Gün aydın./ Axşamın(1z) xeyir./ Nə var,nə yox?-Yaxşıyam, sağ ol. / İşlər necədir? - Ola, sağ ol./ Necəsən?- Baba-tam (Belə də)/ Sağ ol(un)/ Hələlik/ Görüşərik... Слова, обозначающие профессии (tələbə, müəllim, mühəndis...) Монолог: "Представление себя собеседнику". Диалоги: "Знакомство", "На уроке". Работа над новой лексикой и конструкциями.

5. Лексика по теме: "Моя семья" (монолог, диалог) Работа над новой лексикой и конструкциями. Речевой этикет (извинение)

6. Имя числительное. Сочетание количественных числительных с существительными (a) bir, iki, üç... kitab; b) Bu iki alma və dörd armuddur.) Глагол Var. Разграничение конструкций: а) " Наличие - отсутствие предмета" (но владение им) (Mәndo, Səndo, Onda ... kitab(lar)+var // Mənds, Səndo, Onda ... kitab(lar)+ yoxdur); b) "Наличие - отсутствие предмета собственности или одушевленных лии" (Mənim әrim var. Mənim mənzilim var.- Mənim әrim yoxdur. Mənim mənzilim yoxdur.) Диалог "Наличие - отсутствие чего-либо или кого-либо" (Səndə qaşıq var? - Bəli, məndə qaşıq var (Xeyr, məndə qaşıq yoxdur. Məndə çəngəl var). Запомнить (Mən ərdəyəm. - Mən ərdə deyiləm.// Mən evliyəm.// Mən subayam.). Диалог "Прощание" (Bağışlayın, mən getməliyəm. -Yaxşı, sağ olun. Məndən qardaşınıza salam deyin.// Çox sağ olun. Sağlıqla qalın. - Xudahafiz, yaxşı yol.// Yaxşı, mən getməliyəm. - Mən də. Məndən evdəkilərə salam de.// Oldu, çox sağ ol. Hələlik. - Hələlik.) Работа над новой лексикой и конструкциями.

7. Имя числительное. Знакомство с календарем. Диалоги: "Погода", "Времена года". Работа над новой лексикой и конструкциями.

8. Имя прилагательное. Лексика, обозначающая цвет, размер, форму, качество ... предметов. Диалог: "Это какого цвета?" (a) Bu hansı rəngdir?- Bu, qara rəngdir. - Bəs bu? - Bu sarıdır. b) Bu hansi karandaşdır? - Bu, qırmızı karandaşdır. c) Bu yaşıl fincandır? - Bəli. (Xeyr, ağdır.) Вопросы Necə? (к наречиям, глаголам), Nə cür? (к прилагательным) Диалоги: "Какой...? Какая...? (Bu necə kitabdır? - Bu, maraqlı (böyük, pis, təzə...) kitabdir.); "На уроке", "В магазине". Работа над новой лексикой и конструкциями.

9. Послелоги и наречия места, направления (burada, harada, düz, yanında, yaxın, sağa, sola, altında...) Речевой этикет (Buyur(un), zəhmət olmasa, sağ ol...) Диалог: "Где находится...?" (Zəhmət olmasa, deyin, məktəb haradadır? - Orada.- O uzaqdadır? - Xeyr. Yaxındadır. - Sağ ol(un)). Работа над новой лексикой и конструкциями. 
10. Конструкции с Yiyəlik hal (Kimin? Nəyin? афф. - $\boldsymbol{\imath} \boldsymbol{n}^{\circ}$ : Kitabın rəngi qaradır.) и Yerlik hal (Kimdə? Nədə? Harada? aфф. - $\mathbf{d a}{ }^{\circ}$ : Kitab stolun üstündə-dir. Stol divanın yanındadır. Xalça stolun altındadır.) Диалоги: "В комнате", "Где и что находится?", "Встреча на дороге (в университете, в библиотеке...)" Монолог "Описание комнаты, машины..." Работа над новой лексикой и конструкциями.

11. Употребление слова Çox (çox iş, çox dərs/çoxlu kitab (количество) // çox qoca, çox hündür (степень сравнения - "очень") Наречия времени (Nə vaxt?/ Haçan? - gündüz, sabah, indi, axşam, səhər...- Səhər mən məktəbdəyəm. Aynur indi siniftədir.) Работа над новой лексикой и конструкциями.

12. Глагол. Неопределенная форма (афф.-maq/-mok). Личные аффиксы глагола (-am\%

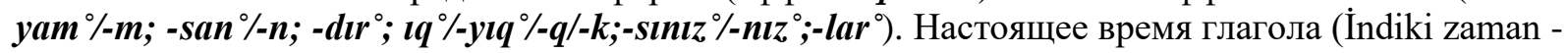
афф.-vr\% $\%$ tr) Образование форм настоящего времени и их использование в составе предложений (Mən universitetdə təhsil alıram.) Порядок слов в предложении. Монологи: "О себе", "Мой день". Диалоги: "Что вы делаете сейчас?", "Какой у вас распорядок дня?" Работа над новой лексикой и конструкциями.

13. Повторительный урок. Сводные диалоги с использование конструкций с существительными, прилагательными, числительными и глаголами в форме настоящего времени. Темами таких диалогов могут быть: "О себе и моем друге", "Моя семья", "Мой день", "На уроке", "Мое свободное время", "В общежитии" и т.д. Работа над новой лексикой и конструкциями.

14. Глагол. Прошедшее время (Şühudi keçmiş (Прошедшее категорическое время) афф.$\boldsymbol{d}^{\circ}$ : Mən saat ald $\boldsymbol{m}$, sən kitab aldın.../// Nəqli keçmiş (Прошедшее результативное время) афф.$\boldsymbol{m} \iota$ \%̧ $^{\circ} \boldsymbol{b}^{\circ}$ : Mən saat almışam, sən kitab almısan, o albom alıb...) [5, 92] Различия в употреблении (примеры) Модель:"Мәn orada idim, O orada idi... - Mən orada olmuşam. O orada olub..." (Различия в употреблении (примеры)) Порядок слов в предложении. Диалоги: "Что вы делаете сейчас и что вы делали вчера?", "Что вы делали вчера утром, днем и вечером?" Работа над новой лексикой и конструкциями.

15. Отрицательная форма глагола (афф.-ma ${ }^{\circ}$-) Образование и использование отрицательных форм настоящего и прошедших времен (примеры) (alıram-almıram, aldım-almadım, almışamalmamışam) Диалоги на утвердительные/отрицательные формы глаголов в настоящем и прошедшем временах. Работа над новой лексикой. Речевой этикет (формы возражения и согласия).

16. Повторительный урок. Сводные диалоги с использование изученных конструкций с глаголами в форме настоящего и прошедших времен. Темами таких монологов и диалогов могут быть: "Любимые занятия членов моей семьи (что делаем вместе и порознь; увлечения)", "Мой друг и его увлечения (что любит/не любит делать), "Мой рабочий день", "Как я (мой друг...) провожу выходные", "На уроке", "Мое свободное время", "В общежитии", "На вечеринке" и др. Работа над новой лексикой и конструкциями.

17. Конструкции с Yönlük hal (Kimə? Nəyə? Haraya? aфф.- $\boldsymbol{a}^{\circ} \% \boldsymbol{y} \boldsymbol{a}^{\circ}$ : Oli qonağ $a$ yer göstərir.) Глаголы, используемые с этим падежом. Диалоги: "Куда вы идете?", "Какой автобус идет в больницу №5?", "В магазине", "В дороге". Работа над новой лексикой и конструкциями. Речевой этикет (вежливые формы обращения, формы просьбы, благодарности).

18. Порядковые числительные (образование (афф.-cı ${ }^{\circ}$ ), употребление в предложениях) Диалоги, монологи: "Биография", "О себе", "Моя семья". Определение времени по часам (a) Saat neçədir? - Saat on ikidir./Üç tamamdır./ Doqquzun yarısıdır./On ikiyə on beş dəqiqə qalır; b) Qatar beş saat iyirmi dəqiqə yol getdi. Avtobus on dəqiqə bundan əvvəl Şəkiyə yola düşdü) Диалог: "Мой день". Работа над новой лексикой и конструкциями. Формы написания автобиографии (примеры, задания).

19.Конструкции с Təsirlik hal (Kimi? Nə?/Nəyi? Haranı? aфф.-ı: Dadaş taxta kəsir./ Dadaş taxtanı kəsir (разница в значении) / Babam ăgac әkir.) Глаголы, используемые с этим падежом. Повторение предыдущего материала. Работа над новой лексикой и конструкциями. Речевой этикет (поздравление, пожелание, приглашение).

20. Конструкции с Çıxışlıq hal (Kimdən? Nədən? Haradan? aфф.- dan : Mən yoldaşımdan məktub aldım.) Глаголы, используемые с этим падежом. Диалоги: "Знакомство (Откуда вы приехали?)", "В деканате". Работа над новой лексикой и конструкциями. Формы написания заявления.

21. Повторительный урок. Сводные диалоги с использование изученных конструкций с существительными в разных падежах и глаголами в форме настоящего и прошедших времен. Темами таких монологов и диалогов могут быть: "Знакомство", "Прощание", "Распорядок дня", "Экскурсия в музей (на выставку...)", "Отдых на каникулах" и др. Работа над новой лексикой и конструкциями. 
22. Конструкция, передающая совместность действия. Послелог їəə и его сокращенная форма -la/-lo. Образование и использование форм (mənim ilə - mənimlə: Mən ofisə maşinla gəlirəm.) Диалог: "Как вы добираетесь до работы и обратно?" Повелительное наклонение глагола (образование, употребление) Модель: -Salam. Zəhmət olmasa, deyin, vağzal haradadır? Mən vağzala necə çatım? - Vağzal buradan uzaq deyil. Әvvəlcə bu küçə ilə gedin. Bir küçəni keçirsiz, sonra sağa. Sağ olun. Диалог: "Как добраться до...?". Работа над новой лексикой и конструкциями.

22. Глагол. Будущее время (Gəti gələcək zaman (Будущее категорическое время) афф.$\boldsymbol{a c a q} \%$-yacaq ${ }^{\circ}$ : Dostum indi gələcək.../// Qeyri-gəti gələcək zaman (Будущее некатегорическое, предположительное время) афф.-ar\%-yar : O indi gələr...) [4,96] Различия в употреблении (примеры) Диалог: "Что вы будете делать завтра?" Порядок слов в предложении. Работа над новой лексикой и конструкциями.

23. Повторительный урок. Сводные диалоги с использование изученных конструкций с существительными в разных падежах и глаголами в форме настоящего, прошедших и будущих времен. Темами монологов, диалогов, ролевых игр могут быть расширенные версии упомянутых монологов, диалогов.

Выводы и рекомендации. Итак, нами была представлена Примерная программа Краткого курса азербайджанского языка для китайских студентов, обучающихся в Азербайджане на русском языке. Она может быть, разумеется, несколько изменена в плане содержания и сетки часов, адаптирована для другого контингента иностранных учащихся. Но учитывая тот факт, что наибольший интерес к изучению азербайджанского языка на данном этапе проявляют именно студенты-китайцы, то целесообразней было бы начать преподавание именно в таких группах иностранных учащихся. А в качестве преподавателей могут выступить преподаватели РКИ, так как в Азербайджане именно они (и в первую очередь, преподаватели Азербайджанского государственного университета нефти и промышленности (АГУНП)) имеют наибольший опыт преподавания русского и азербайджанского языков как иностранных. Преподаватели АГУНП (и в частности, автор статьи) первыми в Республике подготовили первые учебники и пособия по азербайджанскому языку как иностранному, в которых были учтены коммуникативные потребности учащихся и диалог культур, установили методически обоснованное соотношение презентации учебного материала и подготовительных упражнений, представили целый набор коммуникативно значимых тем и ситуаций общения и т.д.

Все сказанное в статье позволяет автору сделать вывод об актуальности проблемы разработки минимума по азербайджанскому языку для иностранных студентов, обучающихся в Азербайджанской Республике на негосударственном языке, о целесообразности реализации данного учебного проекта с целью повышения эффективности учебного процесса и лингвосоциальной адаптации иностранных студентов в новой стране. Формирование некоторого количества компетенций на базе азербайджанского языка будет способствовать развитию диалогу азербайджанской и китайской (и иной) культур, подготовке иностранных специалистов к полноценной межкультурной коммуникации с носителями языка страны пребывания студентов. Условиями успеха же в этой работе являются, с одной стороны, несомненно, мастерство преподавателя, знание им особенностей языковой культуры, а с другой стороны позиция студента открытая, им самим направленная на преодоление затруднений выражения собственных мыслей и понимание собеседника в ситуации взаимодействия его родной и азербайджанской культур.

\section{ЛИТЕРАТУРА}

1. Джабраилова, Р.Г. (2015),"Об актуальности исследования социально-психологических особенностей усвоения азербайджанского языка иностранными студентами", Азимут научных исследований: педагогика и психология, 4 (13), 116 -119. https://cyberleninka.ru/article/n/ob-aktualnosti-issledovaniyasotsialno-psihologicheskih-osobennostey-usvoeniya-azerbaydzhanskogo-yazyka-inostrannymi-studentami

2. Федотова, Н. Л. (2016), "Основные проблемы преподавания русского языка как иностранного в неязыковой среде", IJORS International Journal of Russian Studies. (2016/1), ISSUE No. 5 http://www.ijors.net/issue5_1_2016/articles/fedotova.html

3. Чан Дань Лам. (2014)," Обучение китайских студентов за пределами Китая: проблемы и решение," Успехи современного естествознания, 5 (часть 1), 170-173

4. Q Qasımov, İ.Z., Oliyeva, S.F.(2003), "Müstəqil öyrənənlər üçün Azərbaycan dili", Bakı: İqtisad Universiteti.- 245p. 